\title{
Gamma Knife Radiosurgery for Trigeminal Neuralgia: A Comparison of Dose Protocols
}

\author{
Warren Boling ${ }^{1, *}$, Minwoo Song ${ }^{1}$, Wendy Shih ${ }^{2}$ and Bengt Karlsson ${ }^{3}$ \\ 1 Department of Neurosurgery, Loma Linda University, Loma Linda, CA 92354, USA; MINSong@llu.edu \\ 2 School of Public Health, Loma Linda University, Loma Linda, CA 92354, USA; wshih@llu.edu \\ 3 Department of Neurosurgery, National University Hospital, Singapore 119228, Singapore; \\ nykuttram@yahoo.se \\ * Correspondence: wboling@LLU.edu; Tel.: +1-(909)-558-4419; Fax: +1-(909)-558-4825
}

Received: 24 April 2019; Accepted: 4 June 2019; Published: 10 June 2019

\begin{abstract}
Purpose: A variety of treatment plans including an array of prescription doses have been used in radiosurgery treatment of trigeminal neuralgia (TN). However, despite a considerable experience in the radiosurgical treatment of $\mathrm{TN}$, an ideal prescription dose that balances facial dysesthesia risk with pain relief durability has not been determined. Methods and Materials: This retrospective study of patients treated with radiosurgery for typical TN evaluates two treatment doses in relation to outcomes of pain freedom, bothersome facial numbness, and patient satisfaction with treatment. All patients were treated with radiosurgery for intractable and disabling TN. A treatment dose protocol change from 80 to $85 \mathrm{~Gy}$ provided an opportunity to compare two prescription doses. The variables evaluated were pain relief, treatment side-effect profile, and patient satisfaction. Results: Typical TN was treated with $80 \mathrm{~Gy}$ in 26 patients, and 85 Gy in 37 patients. A new face sensory disturbance was reported after $80 \mathrm{~Gy}$ in $16 \%$ and after $85 \mathrm{~Gy}$ in $27 \%(p=0.4)$. Thirteen failed an 80 Gy dose whereas seven failed an 85 Gy dose. Kaplan-Meier analysis found that at 29 months 50\% failed an 80 Gy treatment compared with 79\% who had durable pain relief after $85 \mathrm{~Gy}$ treatment $(p=0.04)$. Conclusion: The $85 \mathrm{~Gy}$ dose for TN provided a more durable pain relief compared to the $80 \mathrm{~Gy}$ one without a significantly elevated occurrence of facial sensory disturbance.
\end{abstract}

Keywords: trigeminal neuralgia; tic douloureux; radiosurgery; Gamma Knife

\section{Introduction}

Trigeminal neuralgia (TN) is a chronic neuropathic pain condition that affects the regions of the face innervated by the trigeminal nerve. Typical TN causes severe and sudden volleys of shock-like facial pain that lasts a few seconds to a few minutes in the distribution of one or more divisions of the trigeminal nerve. When patients experience attacks of pain that come on repeatedly, the result is a pain condition that is disabling in nature. Typical $\mathrm{TN}$ will have a trigger in the trigeminal nerve division distribution the pain is felt in, which often leads to aversive behavior by the patient to avoid the pain. For example, a trigger inside the mouth may make eating so difficult that poor nutrition results.

Atypical forms of face pain have symptoms that are not shock-like in nature, do not follow the trigeminal nerve distribution, and/or do not have an associated trigger. Atypical face pain my certainly be disabling in nature, however, the treatment options available to typical TN patients are less likely to benefit individuals with atypical face pain.

The etiology of typical TN in most cases is due to vascular compression at the nerve root entry zone as the trigeminal nerve exits the pons. In these cases, microvascular decompression surgery (MVD) in which a small sponge is placed as a cushion between the trigeminal nerve and the offending vessel has a high success rate in eliminating the TN pain. However, the associated risks and inconvenience 
related to the open surgical procedure of MVD lead many individuals with disabling pain, in particular more elderly and frail individuals, to seek out less-invasive treatment approaches such as radiosurgery and percutaneous rhizotomy. Both these approaches have a good success rate in eliminating the pain of TN, but pain recurrence is generally more common compared with MVD.

Lars Leksell introduced radiosurgery as a treatment of trigeminal neuralgia (TN) at the Karolinska Institute in the 1950s [1]. Although interest waned in treating TN with radiosurgery until the early 1990s when there was a substantial increase in the published literature concerning radiosurgery for TN. There is now over the past couple of decades considerable patient experience with radiosurgery in the treatment of TN with the vast majority of publications demonstrating benefit for the severe disabling facial pain [2], particularly in the elderly population who make up the majority of individuals with TN treated by radiosurgery [3].

Radiosurgery treatment variables that have potential to impact both long-term pain relief and occurrence of treatment side-effects include the radiation dose delivered to the nerve, volume or extent of the nerve treated, and anatomical localization of the treatment target. Of these variables, treatment dose has been most frequently studied. Yet, despite a substantial experience in the radiosurgery community, the optimum radiosurgery prescription dose for TN has not been determined.

Herein, the authors present results from their patients with medically intractable TN treated using Gamma Knife radiosurgery (GKR). A retrospective comparison of two treatment dose plans of 80 and $85 \mathrm{~Gy}$ was analyzed for the treatment of typical TN. The variables assessed were pain relief, side-effect profile, and patient satisfaction.

\section{Material and Methods}

\subsection{Patient Population}

All patients were treated for medically intractable TN by the authors at a single institution over a seven year period. Patients (or a family member if the patient was deceased or unable to provide answers to a questionnaire) were contacted by phone or had a face-to-face interview to compete a study questionnaire at follow-up time points after treatment had been completed. The questionnaire inquired about timing of pain relief after GKR, quality and severity of pain, and side effects or complications related to GKR. The patient's subjective assessment of GKR and treatment satisfaction was evaluated by asking two questions: "Are you pleased with GKR?" and "Would you have the procedure again?".

\subsection{GKR Treatment Plan}

Gamma Knife Model 4c (Elekta, Stockholm, Sweden) was used for all treatments. The treatment plan centered the maximum dose on the root entry zone (REZ) of the proximal trigeminal nerve with the $30 \%$ isodose line just contacting the brainstem. Treatment was performed using a $4 \mathrm{~mm}$ collimated single shot. The earlier treatment plan was with a prescription maximum dose delivered to patients of 80 Gy. Later, the protocol was changed to a prescription maximum dose of $85 \mathrm{~Gy}$ in all subsequent patients. These two dose plans were analyzed and compared in treated patients for variables of pain relief, facial numbness, complications of treatment, and patient satisfaction (Figure 1). 


\section{Gy}

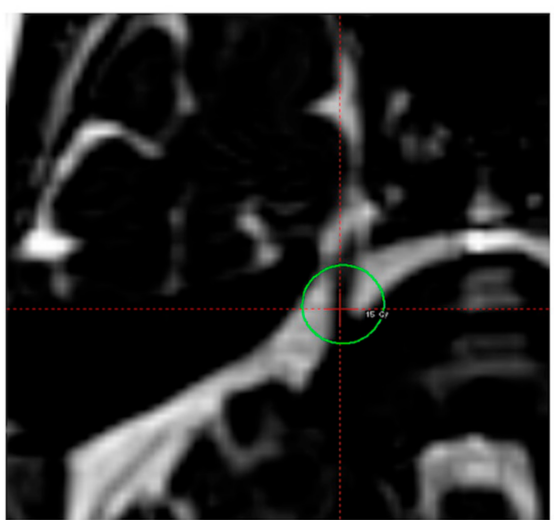

85 Gy

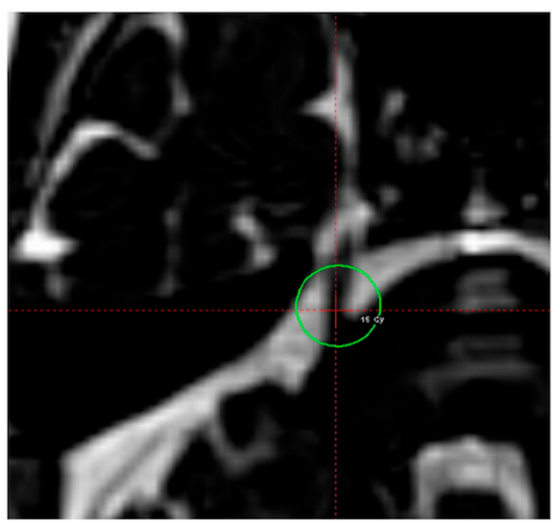

Figure 1. Images of typical corresponding dose plans with the maximum dose targeting the root entry zone (REZ). Green circle is the 15 Gy isodose line.

\subsection{Statistics}

A Kaplan-Meier statistic analyzed the duration of pain freedom after GKR for low- and high-dose groups of patients. The Kaplan-Meier (K-M) survival distributions of the two dose groups were compared using the log rank test. A Fisher's exact or chi square test compared categorical data, such as new onset facial numbness after GKR, patient satisfaction queries, and Barrow Neurological Institute pain intensity (BNI) at last follow-up [4]. $p<0.05$ was considered significant.

\section{Results}

A total of 68 patients were treated with GKR for intractable TN over seven years. Three patients with multiple sclerosis (MS) (all in the 80 Gy group), and two with no available follow-up after treatment (one in each group) were excluded from the analysis. Therefore, in patients with typical TN and post-treatment follow-up, the treatment dose was 80 Gy in 26 individuals, and 85 Gy was delivered to 37 individuals. Mean patient age was 71 years. Twenty-seven were women. Fifteen patients had a procedure for TN prior to GKR (10 in the 80 Gy group, $p=0.6$ ). The mean follow-up after GKR in pain free patients was 37 months (range 6-72 months) in individuals treated with $80 \mathrm{~Gy}$ and 26 months (range 6-52 months) in patients treated with 85 Gy.

A new facial sensory disturbance was reported after an 80 Gy treatment dose in four patients $(16 \%)$ and in $10(27 \%)$ after an 85 Gy treatment dose $(p=0.4)$. Only one individual reported being bothered by numbness in the 80 Gy group and two reported that the sensory change was bothersome in the 85 Gy group. Patients answered "No" to either question of treatment satisfaction (Are you pleased with GKR? or Would you have the procedure again?) in $22 \%$ of the 85 Gy treatment group and in $44 \%$ of the 80 Gy treatment group $(p=0.09$ ).

BNI pain scores at last follow-up were evaluated in each patient. Pain freedom without medication (BNI score of I) was realized in eight individuals treated with $80 \mathrm{~Gy}$ and in 21 treated with $85 \mathrm{~Gy}$, which represented more pain freedom without medication in the 85 Gy group $(p=0.04)$. In addition, significantly more patients who received 85 Gy treatment experienced an overall good result (BNI score I, II, and III) than patients treated with 80 Gy ( 29 with overall good results in the 85 Gy group versus 14 in the 80 Gy group, $p=0.04$ ).

A survival curve was analyzed for both treatment groups using the Kaplan-Meier statistic $(\mathrm{K}-\mathrm{M})$. Recurrent severe pain despite medication or persisting severe pain after GKR was deemed a treatment failure. At the last follow-up, thirteen patients (52\%) who received $80 \mathrm{~Gy}$ treatment dose failed GKR whereas seven patients (19\%) failed GKR after 85 Gy. K-M analysis found at the 29 months time point that $50 \%$ of patients had failed 80 Gy GKR treatment, and at the same time point, $79 \%$ of patients 
had continued pain relief after receiving 85 GY treatment (Figure 2). The K-M analysis demonstrated a significant difference in the achievement of pain relief and durability of response at 29 months $(p=0.04)$.

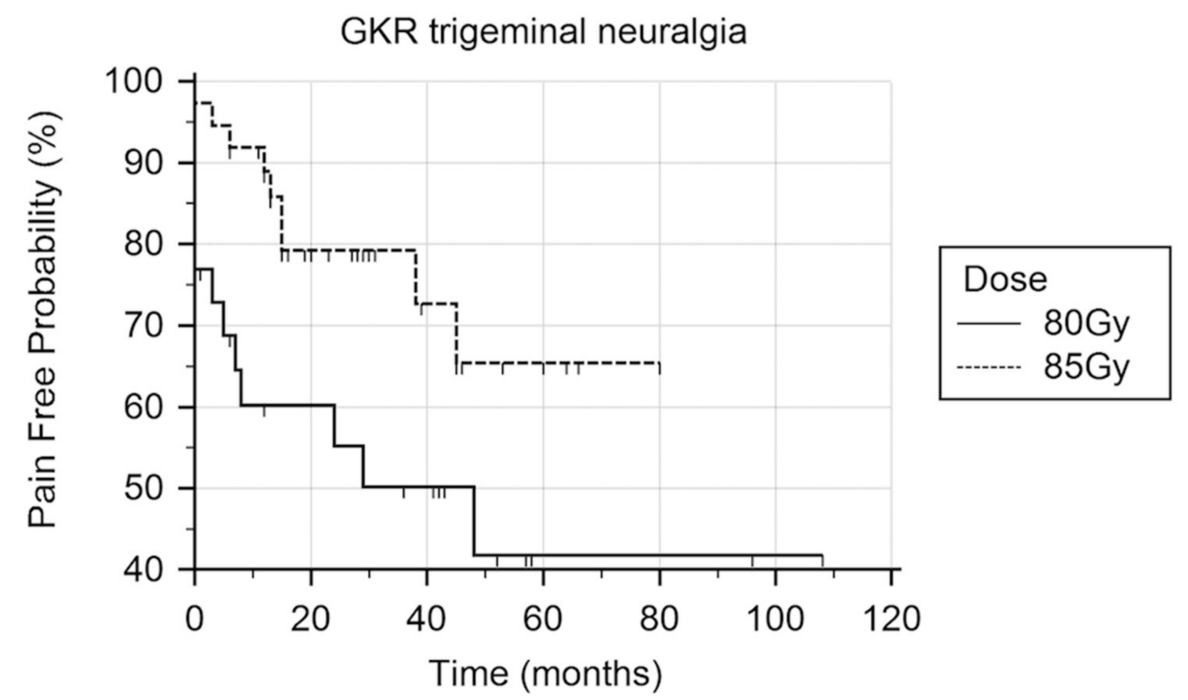

Figure 2. Kaplan-Meier analysis of Gamma Knife radiosurgery for trigeminal neuralgia using two treatment doses. Log rank test demonstrated improved durability and more patients with pain relief in the 85 Gy treated group $(p=0.04)$.

Potential confounders of treatment success were evaluated to determine whether age, new numbness after GKR, surgery before GKR, or length of follow-up differed by GKR dosage (Figure 3). There were significant differences in age and prior surgery in the two GKR dosage groups. As a separate analysis, the effect of dosage on becoming pain free was analyzed while adjusting for potential confounders. In addition, only the effect of age and prior surgery were evaluated as possible confounders. For both analyses, the confounders were found to be not significantly contributing to the dose effect on pain freedom.

\begin{tabular}{cccc}
\hline & $80 \mathrm{~Gy}$ & $\mathbf{8 5} \mathrm{Gy}$ & $p$-Value \\
\hline Age (years) & $67.77(13.57)$ & $74.1(9.78)$ & 0.04 \\
Length of Follow-up & $41.3(26.01)$ & $30.26(21.60)$ & 0.07 \\
New Numbness after GKR & & & 0.07 \\
No & $27(90 \%)$ & $27(71 \%)$ & \\
Yes & $3(10 \%)$ & $11(29 \%)$ & \\
Surgery Prior to GKR & & & 0.002 \\
No & $16(53 \%)$ & $33(89 \%)$ & \\
Yes & $14(47 \%)$ & $4(11 \%)$ & \\
\hline
\end{tabular}

Figure 3. Analysis of potential confounders to pain freedom in the two dosage groups. Patient age and a procedure for trigeminal neuralgia prior to Gamma Knife radiosurgery (GKR) were both found to be significantly different between the dosage groups.

\section{Discussion}

Kondziolka et al. identified that patients who received a 70 Gy dose for treatment of TN fared better with improved pain relief compared to lower prescription doses, and complications were rare [5]. Also, the authors suggested in their patient population that higher treatment doses over 70 Gy yielded 
even better TN pain relief. However, unresolved is the ideal dose that provides the best-possible pain control balanced with the minimum associated radiation complications (Table 1). Additionally, there is no agreement in the published reports of dose escalation. Some authors have identified no benefit for $\mathrm{TN}$ or absence of improved pain relief from treatment with higher prescription doses ranging between 50 and 90 Gy [6-12]. For example, although an improvement in absolute pain relief was not found by Kim et al. with a higher radiation dose, these authors reported 85 Gy provided a more rapid response of pain relief after radiosurgery compared with the 80 Gy dose [13]. Consistent with our results, other authors have identified definite improved pain relief with dose escalation [14-18]. Longhi et al. evaluated radiosurgery for TN targeting the trigeminal nerve root entry zone. The authors identified higher doses in the 80-90 Gy range to be the most effective radiosurgery dose related to a pain free outcome that additionally had low risk of sensory disturbance, although this risk was elevated with the highest treatment dose [14].

Table 1. Studies of prescription dose comparison in radiosurgery of trigeminal neuralgia. * Linear accelerator radiosurgery, REZ = dorsal root entry zone, RG = retrogasserian.

\begin{tabular}{|c|c|c|c|c|}
\hline Study & Max Dose to Nerve & $\begin{array}{l}\text { Dose Related Pain } \\
\text { Freedom }\end{array}$ & $\begin{array}{l}\text { Facial Numbness } \\
\text { Dose Related }\end{array}$ & $\begin{array}{l}\text { Radiosurgery } \\
\text { Target }\end{array}$ \\
\hline $\begin{array}{l}\text { Kondziolka et al. } \\
{[5]}\end{array}$ & $\begin{array}{l}\leq 65 \mathrm{~Gy} \\
\geq 70 \mathrm{~Gy}\end{array}$ & $\begin{aligned} \text { Yes } & \geq 70 \mathrm{~Gy} \\
p & =0.02\end{aligned}$ & No relationship & REZ \\
\hline Pollock et al. [8] & $\begin{array}{l}70 \mathrm{~Gy} \\
90 \mathrm{~Gy}\end{array}$ & No difference & $\begin{array}{l}\text { Yes. Numbness and } \\
\text { dysesthesia }\end{array}$ & REZ \\
\hline Alpert et al. [14] & $\begin{array}{l}\leq 80 \mathrm{~Gy} \\
85 \mathrm{~Gy} \\
\geq 90 \mathrm{~Gy}\end{array}$ & $\begin{array}{c}\text { Yes, with escalating } \\
\text { doses } \\
p<0.001\end{array}$ & No relationship & $\begin{array}{c}\text { REZ } \\
\pm \text { second shot } \\
3-4 \mathrm{~mm} \text { more distal }\end{array}$ \\
\hline Sheehan et al. [9] & 50-90 Gy & No difference & No relationship & REZ \\
\hline Tawk et al. [10] & 70,80 , or $90 \mathrm{~Gy}$ & No difference & Trend to dose relationship & REZ \\
\hline $\begin{array}{l}\text { Morbidini-Gaffney } \\
\text { et al. [18] }\end{array}$ & $\begin{array}{c}<80 \mathrm{~Gy} \\
85 \mathrm{~Gy} \\
>85 \mathrm{~Gy}\end{array}$ & $\begin{array}{c}\text { Yes }<85 \text { Gy } \\
p<0.001\end{array}$ & & $\begin{array}{c}\text { REZ } \\
\pm \text { second shot } \\
2-4 \mathrm{~mm} \text { more distal }\end{array}$ \\
\hline Régis et al. [11] & 70-90 Gy & No difference & No relationship & $\begin{array}{l}7.5 \mathrm{~mm} \text { anterior to } \\
\text { pons }\end{array}$ \\
\hline Fountas et al. [7] & $75-85$ Gy & No difference & & REZ \\
\hline Longhi et al. [15] & $\begin{array}{l}75-95 \mathrm{~Gy} \\
>80 \mathrm{~Gy}\end{array}$ & $\begin{array}{c}\text { Yes }>80 \mathrm{~Gy} \\
p=0.008\end{array}$ & $\begin{array}{l}>90 \text { Gy increased } \\
\text { numbness }\end{array}$ & REZ \\
\hline Chen et al. * [6] & 85 or $90 \mathrm{~Gy}$ & No difference & & $\begin{array}{l}\text { Cisternal nerve } \\
\text { segment }\end{array}$ \\
\hline Matsuda et al. [16] & 80 or $90 \mathrm{~Gy}$ & No difference & $\begin{array}{l}\text { Trend to more numbness } \\
\text { in } 90 \text { Gy RG target }\end{array}$ & $\begin{array}{c}80 \text { Gy REZ } \\
90 \text { Gy RG target }\end{array}$ \\
\hline Kim et al. [13] & 75 or $85 \mathrm{~Gy}$ & No difference & No relationship & REZ \\
\hline Smith et al. * [17] & 70 or $90 \mathrm{~Gy}$ & Yes, at one year & Trend to dose relationship & REZ \\
\hline Zhang et al. [12] & 75 or $90 \mathrm{~Gy}$ & No difference & No dose relationship & $\begin{array}{l}\text { Cisternal portion of } \\
\text { nerve with one or } \\
\text { two isocenters }\end{array}$ \\
\hline Kotecha et al. [19] & $\leq 82,83-86$, or $\geq 90 \mathrm{~Gy}$ & Improved > $82 \mathrm{~Gy}$ & $\begin{array}{c}\text { No dose relationship } \\
\text { prescription doses } \geq 83 \mathrm{~Gy}\end{array}$ & REZ \\
\hline Massager et al. [20] & $\begin{array}{l}70-85 \text { Gy, } 90 \text { Gy, or } \\
90 \text { Gy with shielding }\end{array}$ & $\begin{array}{l}\text { No, trend to better pain } \\
\text { freedom in higher dose }\end{array}$ & $\begin{array}{l}\text { Yes. Numbness related } \\
\text { with higher dose }\end{array}$ & $\begin{array}{l}\text { Anterior cisternal } \\
\text { nerve segment }\end{array}$ \\
\hline $\begin{array}{l}\text { Villavicencio et al. } \\
*[21]\end{array}$ & $\begin{array}{l}\text { Range of } 50-80 \mathrm{~Gy}, \\
\text { median } 75 \mathrm{~Gy}\end{array}$ & $\begin{array}{l}\text { Yes, related with longer } \\
\text { nerve segment treated }\end{array}$ & Yes & REZ \\
\hline
\end{tabular}

Morbidini-Gaffney et al., in a follow-on study of patients reported in Alpert et al. [14], assessed patients treated with TN in order to evaluate efficacy of two versus one-isocenter treatment plans as well as an evaluation of radiation dose escalation [18]. The results were that two isocenters plus patients receiving greater than 85 Gy had a longer duration of good treatment response compared with lower treatment doses and a single isocenter. There were no identified facial dysesthesias although 
$11 \%$ reported mild facial numbness. In a conflicting report from Zhang et al. patients with refractory TN were treated with a maximum dose of $75-90$ Gy using either one $(n=41)$ or two $(n=32)$ isocenters. The authors found no difference in pain relief or sensory disturbance with higher dose, but the patients with multiple-isocenter treatment plans did experience more numbness or paresthesia in the trigeminal distribution [12].

Smith et al. used linear accelerator-based radiosurgery to treat TN [17]. Over an initial time period, 28 patients received doses between 70 and $85 \mathrm{~Gy}$. The subsequently treated 82 patients were prescribed a radiation dose of $90 \mathrm{~Gy}$, with a treatment plan of the $30 \%$ isodose line touching the brainstem. The treatment plan was further modified later with the goal of increasing the dose at the root entry zone so that the $50 \%$ isodose line was tangential to the pons in 59 patients. Patients treated with 90 Gy had superior pain relief at one year follow-up and more rapid resolution of pain relief after treatment. There was no significant difference in facial numbness between the treatment groups. Young et al. reported over a five year follow-up after 90 Gy GKR treatment for TN that over $70 \%$ of patients were pain free with or without medication [22]. The authors concluded that higher-dose treatment was effective in treating $\mathrm{TN}$, that pain relief was more likely in patients with facial numbness post treatment, and the authors commented that a 90 Gy prescription dose may be associated with an increase in bothersome sensory complications in comparison with lower treatment doses. Pollock et al. also identified increased numbness and dysesthesia in their patients treated with 90 Gy compared with lower doses [23]. The University of CaliforniaSan Diego TN treatment experience was reviewed by Taich et al., who identified elevated risk of bothersome facial numbness with treatment doses greater than 85 Gy [24]. Radiosurgery dose escalation was studied retrospectively in $870 \mathrm{TN}$ patients by Kotecha et al. who analyzed patients divided into groups of delivered doses: $\leq 82,83-86$, and $\geq 90$ Gy [19]. The investigators identified that dose escalation above 82 Gy resulted in improved pain relief, but with elevated risk of treatment-related facial numbness. However, facial numbness resulted in similar proportions in patients treated at prescription doses $\geq 83 \mathrm{~Gy}$. Massager et al. [20] analyzed 358 patients with GKR-treated TN that targeted the anterior cisternal portion of the trigeminal nerve. The Brussels study divided patients into three different dosimetric treatment groups, which revealed rates of trigeminal numbness and pain relief closely related to the radiation dose delivered to the retrogasserian portion of the nerve. A similar relationship was reported by Villavicencio et al. [21]. This group treated TN using CyberKnife (Accuray Inc., Sunnyvale, CA, USA) radiosurgery, which resulted in better pain relief and increased hypesthesia rates in those patients receiving higher radiation dose with a longer nerve segment treated.

High-resolution MRI or CT myelography allows for the trigeminal nerve to be clearly delineated from its exit at the brainstem to Meckel's cave. The imaging well-defined anatomy of the trigeminal nerve allows for accurate radiosurgery targeting at any point along its course in the subarachnoid cistern. The REZ has been the most common radiosurgery treatment site of TN likely because the REZ has a long history in neurosurgery as a lesioning target for a variety of pain conditions. However, in an effort to reduce the pontine radiation dose, some radiosurgery users have moved the target more anteriorly along the nerve [17]; although, few investigators have critically analyzed anatomical targeting differences related to outcome from treatment of TN (Table 2). Among the few authors who have critically evaluated a more anterior treatment plan, Matsuda et al. found no difference in pain freedom and a trend to more facial numbness using an anterior retrogasserian target in comparison to a REZ target, although the anterior target received a higher dose in their patients [16]. Park et al. identified no difference in pain freedom or facial numbness in patients treated with REZ versus an anterior retrogasserian target [25]. Rashid et al. treated with 90 Gy maximum dose to REZ and retrogasserian targets. Comparison of the two treatment groups identified improved pain freedom in the REZ target patients, and no difference in the development of new facial numbness [26]. Xu et al. retrospectively evaluated 141 patients with TN treated using GKR prescribed to a maximum dose of 80 Gy targeting either the REZ or the retrogasserian nerve. Their analysis revealed the REZ provided more durable pain relief with similar initial efficacy, but that facial numbness was more common in the 
REZ-treated patients [27]. Sharim et al., using linear accelerator-based radiosurgery, found no benefit in regard to face hypesthesia and no difference in pain relief rate with trigeminal nerve targets more anterior to the REZ [28]. Strategies such as anterior nerve targeting as well as techniques to correct dosimetry are effective in reduction of the brainstem total dose [29], and there is limited evidence that the risk of facial numbness may be reduced with a more anterior treatment target. This topic was reviewed by the International Radiosurgery Society Practice Guideline committee, which concluded that there is level II evidence that an anterior target reduces radiosurgery-related facial numbness with a similar benefit of pain reduction compared to REZ [30].

Table 2. Comparison studies of radiosurgery targets in the treatment of trigeminal neuralgia (TN). $\mathrm{REZ}=$ dorsal root entry zone.

\begin{tabular}{|c|c|c|c|}
\hline Study & $\begin{array}{l}\text { Radiosurgery Target and } \\
\text { Max Dose to Nerve }\end{array}$ & Pain Freedom & $\begin{array}{l}\text { Facial Numbness } \\
\text { Target Related }\end{array}$ \\
\hline Matsuda et al. [16] & $\begin{array}{c}80 \text { Gy REZ } \\
90 \text { Gy retrogasserian target }\end{array}$ & No difference & $\begin{array}{l}\text { Trend to more numbness in } \\
\text { the anterior target patients }\end{array}$ \\
\hline Park et al. [25] & $\begin{array}{l}80-90 \text { Gy REZ } \\
\text { or retrogasserian target }\end{array}$ & No difference & No relationship \\
\hline Xu et al. [27] & 80 Gy REZ or retrogasserian target & $\begin{array}{l}\text { Similar initial pain relief. } \\
\text { REZ more durable }\end{array}$ & $\begin{array}{l}\text { More facial numbness in the } \\
\text { REZ target patients }\end{array}$ \\
\hline Rashid et al. [26] & $\begin{array}{l}90 \text { Gy REZ } \\
\text { or retrogasserian target }\end{array}$ & $\begin{array}{l}\text { REZ target better } \\
\text { pain control }\end{array}$ & No relationship \\
\hline
\end{tabular}

A few reports have described treating a greater nerve volume in an effort to improve pain-free results by employing an additional isocenter along the length of the nerve (Table 3 ). In a prospective randomized study, Flickinger et al. found an elevated risk of facial numbness with a two-isocenter treatment plan without improved pain relief [31]. However, in other published studies, Pollock et al. [8] and Alpert et al. [14] identified no relationship between nerve volume treatment and the development of facial numbness. Morbidini-Gaffney et al. [18], in a follow-on study from Alpert et al. [14], described in their patient population a significant positive correlation of multiple isocenters and higher treatment dose with pain freedom. They reported mild numbness in $11 \%$ of patients, although the hypesthesia risk associated with different treatment plans was not clear in the publication. Zhao et al. reported 247 patients who underwent a multi-isocenter GKR treatment of two adjacent $4 \mathrm{~mm}$ shots distributed along the trigeminal nerve with a maximum dose of $88 \mathrm{~Gy}$ [32]. In this group of patients treated, facial numbness occurred in $32.0 \%$, of which $3.6 \%$ were identified as bothersome. Wolf et al. found in their TN patents treated with GKR no relationship of pain freedom with nerve length or nerve volume treated [33]. The authors did identify a relationship of better durability of pain relief at one year in patients with higher treatment dose delivered to smaller nerve volumes. Overall new facial numbness was reported in $23.6 \%$, although only $3.6 \%$ experienced bothersome numbness. The preponderance of published studies analyzing multiple-isocenter treatment plans found no difference in pain-free outcome from more than one treatment shot, and that treatment-related facial numbness is not a consistently identified relationship with multi-shot treatment plans. However, the best evidence to date was from a single prospective randomized study [31], which found a significantly elevated risk of sensory changes related with a two-isocenter plan.

Hypesthesia was rare in our patients ( $22 \%$ of all individuals treated for $\mathrm{TN}$ ) with no difference between the two treatment doses. Most individuals treated by the authors who developed a sensory disturbance were not bothered by the numbness, typically patients commented that an improved quality of life resulting from resolution of the disabling pain was more relevant compared to the sensory change. Some patients also commented that a new facial numbness was an acceptable trade-off for pain relief. However, it should be noted that in three patients ( $21 \%$ of patients with a post-treatment sensory disturbance and $5 \%$ of all treated patients) bothersome sensory change was GKR treatment related, and the resulting dysesthesia in these individuals is reasonably regarded as a toxicity of the radiosurgery treatment. Seventy-eight percent of patients treated with 85 Gy maximum dose to the 
trigeminal nerve responded that they were pleased with the GKR and would choose the treatment again, which is similar to other reports of patient satisfaction. Debono et al. reported $86.5 \%$ patient satisfaction with LINAC radiosurgery of 90 Gy dose for trigeminal neuralgia [34].

Table 3. Radiosurgery studies of multi-isocenter treatment plans. REZ = dorsal root entry zone.

\begin{tabular}{|c|c|c|c|c|}
\hline Study & Max Dose to Nerve & Pain Freedom & Facial Numbness & Radiosurgery Target \\
\hline $\begin{array}{l}\text { Flickinger et al. } \\
\qquad[31]\end{array}$ & $\begin{array}{l}75 \text { Gy one or two } \\
\text { isocenters }\end{array}$ & No difference & $\begin{array}{l}\text { Increased numbness } \\
\text { with two isocenters }\end{array}$ & $\begin{array}{c}\text { REZ } \\
\text { 土second shot 2-4 mm } \\
\text { distal to brainstem }\end{array}$ \\
\hline Pollock et al. [23] & $\begin{array}{c}70-90 \mathrm{~Gy} \\
\text { one or two isocenters }\end{array}$ & $\begin{array}{c}\text { Trend for longer length } \\
\text { of treated nerve }\end{array}$ & $\begin{array}{l}\text { No relation with nerve } \\
\text { volume treated }\end{array}$ & $\begin{array}{c}\text { Single anterior target } \\
\pm \text { second shot along } \\
\text { nerve }\end{array}$ \\
\hline $\begin{array}{l}\text { Morbidini-Gaffney } \\
\text { et al. [18] }\end{array}$ & $\begin{array}{c}<80 \\
85 \\
\text { or }>85 \text { Gy } \\
\text { one or two isocenters }\end{array}$ & $\begin{array}{l}\text { Improved in } \geq 85 \mathrm{~Gy} \\
\text { dose and number of } \\
\text { isocenters treated }\end{array}$ & $\begin{array}{l}11 \% \text { mild numbness, } \\
\text { unknown relation to } \\
\text { number of isocenters }\end{array}$ & $\begin{array}{c}\text { REZ } \\
\pm \text { second shot } 2-4 \mathrm{~mm} \\
\text { more distal }\end{array}$ \\
\hline Zhao et al. [32] & $88 \mathrm{~Gy}$ and two isocenters & & $\begin{array}{l}32 \% \text { numbness } \\
3.6 \% \text { bothersome } \\
\text { numbness }\end{array}$ & $\begin{array}{c}\text { Two adjacent } 4 \mathrm{~mm} \\
\text { shots commencing at } \\
\text { the REZ }\end{array}$ \\
\hline Wolf et al. [33] & $\begin{array}{l}\text { 80-90 Gy initial GKR, } \\
\quad 65-70 \text { Gy } \\
\text { repeat GKR, } 80 \text { Gy } \\
\text { shorter-nerve treatment, } 85 \\
\text { Gy longer-nerve treatment }\end{array}$ & $\begin{array}{l}\text { No relationship to nerve } \\
\text { length or volume treated } \\
\text { More durable in higher } \\
\text { dose to smaller volume }\end{array}$ & $\begin{array}{l}\text { Numbness in } 23.6 \% \text {, } \\
\text { bothersome in } 3.6 \%\end{array}$ & REZ \\
\hline
\end{tabular}

Interventions that impact neural function are typically described as either ablative or modulatory. This has been discussed by other authors in regard to treatment of $\mathrm{TN}[35,36]$. A seeming contradiction in discussions of radiosurgery for $\mathrm{TN}$ is that facial numbness resulting from radiosurgery is commonly labeled a treatment complication. A degree of facial numbness in the trigeminal branch of pain is a desired result of an ablative technique such as radiofrequency lesioning, which correlates positively with pain relief [37]. In fact, radiosurgery is more likely to yield pain relief in patients experiencing a facial sensory deficit, a fact that argues for an ablative mechanism [22,38]. However, neuromodulation is a better description of radiosurgery in the majority of patients who are able to realize pain relief without a sensory disturbance. Likewise, a dose-response relationship with hypesthesia has not been clearly demonstrated in studies of dose escalation (Table 1). In animal models of radiosurgery, a histopathological dose relationship has been demonstrated [39,40]. Minor changes become evident at about 80 Gy and necrosis is seen after the delivery of 100 Gy to the trigeminal nerve. In general, investigations up to now support elements of both neuromodulation and ablation as the physiological mechanism underlying radiosurgery treatment of $\mathrm{TN}$, particularly at the radiation doses used to treat patients.

The optimal radiosurgery treatment dose for TN should strike a balance between providing the most robust pain relief and the least possible risk of radiation-induced complications. The only radiation-related complication identified in our patient population was hemifacial dysesthesia, which was rare (4\% in the 80 Gy treatment group and $5.4 \%$ in the 85 Gy group) and not significantly different between the two prescription doses. However, the patients who received the higher treatment dose of $85 \mathrm{~Gy}$ did realize a more robust treatment response compared with those who received the $80 \mathrm{~Gy}$ dose (79\% versus 50\% pain relief, respectively, at 29 months, $\mathrm{K}-\mathrm{M}$ analysis, $p=0.04)$. The major limitations of our study are a retrospective analysis of outcome measures and a shorter follow-up period in the high-dose, 85 Gy, treatment group. 


\section{Conclusions}

We identified in our patients with typical TN that a GKR prescription dose treatment of $85 \mathrm{~Gy}$ provided a longer lasting and more robust pain relief compared to a dose of $80 \mathrm{~Gy}$. A facial sensory change occurred in $11 \%$ more of the individuals in the 85 Gy treatment group, although the difference did not reach statistical significance $(p=0.4)$. Dysesthesia or a bothersome facial numbness was rare, and these complications were equally distributed between the treatment groups. The majority of patients were satisfied with radiosurgery for TN and, as expected, patients treated with the more effective dose of 85 Gy demonstrated a trend of greater treatment satisfaction. However, there is no agreement in the published studies of efficacy of dose escalation for the radiosurgical treatment of TN, and determination of the ideal dose prescription that maximizes pain relief and minimizes dysesthesia will likely require a randomized prospective clinical trial.

Author Contributions: All authors contributed substantially and meaningfully to the manuscript and research: Conceptualization, W.B. and B.K.; methodology, W.B.; investigation, W.B.; data curation, W.B. and B.K.; writing—review and editing, W.B., M.S., and B.K.

Conflicts of Interest: The authors declare no conflict of interest.

\section{References}

1. Niranjan, A.; Maitz, A.H.; Lunsford, A.; Gerszten, P.C.; Flickinger, J.C.; Kondziolka, D.; Lunsford, L.D. Radiosurgery techniques and current devices. Prog. Neurol. Surg. 2007, 20, 50-67. [PubMed]

2. Régis, J.; Tuleasca, C. Fifteen years of Gamma Knife surgery for trigeminal neuralgia in the Journal of Neurosurgery. History of a revolution in functional neurosurgery. J. Neurosurg. 2011, 115, 2-7. [CrossRef] [PubMed]

3. Cohen, J.; Mousavi, S.H.; Faraji, A.H.; Akpinar, B.; Monaco, E.A.; Flickinger, J.C.; Niranjan, A.; Lunsford, L.D. Stereotactic Radiosurgery as Initial Surgical Management for Elderly Patients with Trigeminal Neuralgia. Stereotact. Funct. Neurosurg. 2017, 95, 158-165. [CrossRef] [PubMed]

4. Rogers, C.L.; Shetter, A.G.; Fiedler, J.A.; Smith, K.A.; Han, P.P.; Speiser, B.L. Gamma knife radiosurgery for trigeminal neuralgia: the initial experience of The Barrow Neurological Institute. Int. J. Radiat. Oncol. Biol. Phys. 2000, 47, 1013-1019. [CrossRef]

5. Kondziolka, D.; Lunsford, L.D.; Flickinger, J.C.; Young, R.F.; Vermeulen, S.; Duma, C.M.; Jacques, D.B.; Rand, R.W.; Regis, J.; Peragut, J.C.; et al. Stereotactic radiosurgery for trigeminal neuralgia: A multiinstitutional study using the gamma unit. J. Neurosurg. 1996, 84, 940-945. [CrossRef] [PubMed]

6. Chen, J.C.; Greathouse, H.E.; Girvigian, M.R.; Miller, M.J.; Liu, A.; Rahimian, J. Prognostic factors for radiosurgery treatment of trigeminal neuralgia. Neurosurgery 2008, 62, A53-A60. [CrossRef] [PubMed]

7. Fountas, K.N.; Smith, J.R.; Lee, G.P.; Jenkins, P.D.; Cantrell, R.R.; Sheils, W.C. Gamma Knife stereotactic radiosurgical treatment of idiopathic trigeminal neuralgia: Long-term outcome and complications. Neurosurg. Focus 2007, 23, E8. [CrossRef] [PubMed]

8. Pollock, B.E.; Phuong, L.K.; Foote, R.L.; Stafford, S.L.; Gorman, D.A. High-dose trigeminal neuralgia radiosurgery associated with increased risk of trigeminal nerve dysfunction. Neurosurgery 2001, 49, 58-62. [PubMed]

9. Sheehan, J.; Pan, H.C.; Stroila, M.; Steiner, L. Gamma knife surgery for trigeminal neuralgia: Outcomes and prognostic factors. J. Neurosurg. 2005, 102, 434-441. [CrossRef] [PubMed]

10. Tawk, R.G.; Duffy-Fronckowiak, M.; Scott, B.E.; Alberico, R.A.; Diaz, A.Z.; Podgorsak, M.B.; Plunkett, R.J.; Fenstermaker, R.A. Stereotactic gamma knife surgery for trigeminal neuralgia: Detailed analysis of treatment response. J. Neurosurg. 2005, 102, 442-449. [CrossRef] [PubMed]

11. Régis, J.; Metellus, P.; Hayashi, M.; Roussel, P.; Donnet, A.; Bille-Turc, F. Prospective controlled trial of gamma knife surgery for essential trigeminal neuralgia. J. Neurosurg. 2006, 104, 913-924. [CrossRef] [PubMed]

12. Zhang, X.; Li, P.; Zhang, S.; Gong, F.; Yang, S.; Wang, W. Effect of radiation dose on the outcomes of gamma knife treatment for trigeminal neuralgia: A multi-factor analysis. Neurol. India 2014, 62, 400-405. [PubMed]

13. Kim, Y.H.; Kim, D.G.; Kim, J.W.; Han, J.H.; Chung, H.T.; Paek, S.H. Is it effective to raise the irradiation dose from 80 to $85 \mathrm{~Gy}$ in gamma knife radiosurgery for trigeminal neuralgia? Stereotact. Funct. Neurosurg. 2010, 88, 169-176. [CrossRef] [PubMed] 
14. Alpert, T.E.; Chung, C.T.; Mitchell, L.T.; Hodge, C.J.; Montgomery, C.T.; Bogart, J.A.; Kim, D.Y.; Bassano, D.A.; Hahn, S.S. Gamma knife surgery for trigeminal neuralgia: improved initial response with two isocenters and increasing dose. J. Neurosurg. 2005, 102, 185-188. [CrossRef] [PubMed]

15. Longhi, M.; Rizzo, P.; Nicolato, A.; Foroni, R.; Reggio, M.; Gerosa, M. Gamma knife radiosurgery for trigeminal neuralgia: results and potentially predictive parameters-Part I: Idiopathic trigeminal neuralgia. Neurosurgery 2007, 61, 1254-1260. [CrossRef] [PubMed]

16. Matsuda, S.; Serizawa, T.; Nagano, O.; Ono, J. Comparison of the results of 2 targeting methods in Gamma Knife surgery for trigeminal neuralgia. J. Neurosurg. 2008, 109, 185-189. [CrossRef] [PubMed]

17. Smith, Z.A.; Gorgulho, A.A.; Bezrukiy, N.; McArthur, D.; Agazaryan, N.; Selch, M.T.; De Salles, A.A. Dedicated linear accelerator radiosurgery for trigeminal neuralgia: A single-center experience in 179 patients with varied dose prescriptions and treatment plans. Int. J. Radiat. Oncol. Biol. Phys. 2011, 81, 225-231. [CrossRef] [PubMed]

18. Morbidini-Gaffney, S.; Chung, C.T.; Alpert, T.E.; Newman, N.; Hahn, S.S.; Shah, H.; Mitchell, L.; Bassano, D.; Darbar, A.; Bajwa, S.A.; et al. Doses greater than 85 Gy and two isocenters in Gamma Knife surgery for trigeminal neuralgia: Updated results. J. Neurosurg. 2006, 105, 107-111. [CrossRef]

19. Kotecha, R.; Kotecha, R.; Modugula, S.; Murphy, E.S.; Jones, M.; Kotecha, R.; Reddy, C.A.; Suh, J.H.; Barnett, G.H.; Neyman, G.; et al. Trigeminal Neuralgia Treated with Stereotactic Radiosurgery: The Effect of Dose Escalation on Pain Control and Treatment Outcomes. Int. J. Radiat. Oncol. Biol. Phys. 2016, 96, 142-148. [CrossRef]

20. Massager, N.; Murata, N.; Tamura, M.; Devriendt, D.; Levivier, M.; Régis, J. Influence of nerve radiation dose in the incidence of trigeminal dysfunction after trigeminal neuralgia radiosurgery. Neurosurgery 2007, 60, 681-687. [CrossRef]

21. Villavicencio, A.T.; Lim, M.; Burneikiene, S.; Romanelli, P.; Adler, J.R.; McNeely, L.; Chang, S.D.; Fariselli, L.; McIntyre, M.; Bower, R.; et al. Cyberknife radiosurgery for trigeminal neuralgia treatment: A preliminary multicenter experience. Neurosurgery 2008, 62, 647-655. [CrossRef] [PubMed]

22. Young, B.; Shivazad, A.; Kryscio, R.J.; St Clair, W.; Bush, H.M. Long-term outcome of high-dose $\gamma$ knife surgery in treatment of trigeminal neuralgia. J. Neurosurg. 2013, 119, 1166-1175. [CrossRef] [PubMed]

23. Pollock, B.E.; Phuong, L.K.; Gorman, D.A.; Foote, R.L.; Stafford, S.L. Stereotactic radiosurgery for idiopathic trigeminal neuralgia. J. Neurosurg. 2002, 97, 347-353. [CrossRef] [PubMed]

24. Taich, Z.J.; Goetsch, S.J.; Monaco, E.; Carter, B.S.; Ott, K.; Alksne, J.F.; Chen, C.C. Stereotactic Radiosurgery Treatment of Trigeminal Neuralgia: Clinical Outcomes and Prognostic Factors. World Neurosurg 2016, 90, 604-612. [CrossRef] [PubMed]

25. Park, S.H.; Hwang, S.K.; Kang, D.H.; Park, J.; Hwang, J.H.; Sung, J.K. The retrogasserian zone versus dorsal root entry zone: comparison of two targeting techniques of gamma knife radiosurgery for trigeminal neuralgia. Acta Neurochir. 2010, 152, 1165-1170. [CrossRef] [PubMed]

26. Rashid, A.; Pintea, B.; Kinfe, T.M.; Surber, G.; Hamm, K.; Boström, J.P. LINAC stereotactic radiosurgery for trigeminal neuralgia-retrospective two-institutional examination of treatment outcomes. Radiat. Oncol. 2018, 13, 153. [CrossRef]

27. Xu, Z.; Schlesinger, D.; Moldovan, K.; Przybylowski, C.; Sun, X.; Lee, C.C.; Yen, C.P.; Sheehan, J. Impact of target location on the response of trigeminal neuralgia to stereotactic radiosurgery. J. Neurosurg. 2014, 120 , 716-724. [CrossRef]

28. Sharim, J.; Lo, W.L.; Kim, W.; Chivukula, S.; Tenn, S.; Kaprealian, T.; Pouratian, N. Radiosurgical target distance from the root entry zone in the treatment of trigeminal neuralgia. Pract. Radiat. Oncol. 2017, 7, 221-227. [CrossRef]

29. Régis, J. High-dose trigeminal neuralgia radiosurgery associated with increased risk of trigeminal nerve dysfunction. Neurosurgery 2002, 50, 1401-1402.

30. Tuleasca, C.; Régis, J.; Sahgal, A.; De Salles, A.; Hayashi, M.; Ma, L.; Martínez-Álvarez, R.; Paddick, I.; Ryu, S.; Slotman, B.J.; et al. Stereotactic radiosurgery for trigeminal neuralgia: A systematic review International Stereotactic Radiosurgery Society practice guidelines. J. Neurosurg. 2019, 130, 733-757. [CrossRef]

31. Flickinger, J.C.; Pollock, B.E.; Kondziolka, D.; Phuong, L.K.; Foote, R.L.; Stafford, S.L.; Lunsford, L.D. Does increased nerve length within the treatment volume improve trigeminal neuralgia radiosurgery? A prospective double-blind, randomized study. Int. J. Radiat. Oncol. Biol. Phys. 2001, 51, 449-454. [CrossRef] 
32. Zhao, H.; Shen, Y.; Yao, D.; Xiong, N.; Abdelmaksoud, A.; Wang, H. Outcomes of Two-Isocenter Gamma Knife Radiosurgery for Patients with Typical Trigeminal Neuralgia: Pain Response and Quality of Life. World Neurosurg. 2018, 109, e531-e538. [CrossRef] [PubMed]

33. Wolf, A.; Tyburczy, A.; Ye, J.C.; Fatterpekar, G.; Silverman, J.S.; Kondziolka, D. The relationship of dose to nerve volume in predicting pain recurrence after stereotactic radiosurgery in trigeminal neuralgia. J. Neurosurg. 2018, 128, 891-896. [CrossRef] [PubMed]

34. Debono, B.; Lotterie, J.A.; Sol, J.C.; Bousquet, P.; Duthil, P.; Monfraix, S.; Lazorthes, Y.; Sabatier, J.; Latorzeff, I. Dedicated Linear Accelerator Radiosurgery for Classic Trigeminal Neuralgia: A Single-Center Experience with Long-Term Follow-Up. World Neurosurg. 2019, 121, e775-e785. [CrossRef] [PubMed]

35. Lopez, B.C.; Hamlyn, P.J.; Zakrzewska, J.M. Stereotactic radiosurgery for primary trigeminal neuralgia: state of the evidence and recommendations for future reports. J. Neurol. Neurosurg. Psychiatry 2004, 75, 1019-1024. [CrossRef] [PubMed]

36. Régis, J.; Carron, R.; Park, M. Is radiosurgery a neuromodulation therapy? A 2009 Fabrikant award lecture. J. Neurooncol. 2010, 98, 155-162. [CrossRef] [PubMed]

37. Nugent, G.R. Technique and results of 800 percutaneous radiofrequency thermocoagulations for trigeminal neuralgia. Appl. Neurophysiol. 1982, 45, 504-507. [PubMed]

38. Pollock, B.E. Radiosurgery for trigeminal neuralgia: Is sensory disturbance required for pain relief? J. Neurosurg. 2006, 105, 103-106. [CrossRef]

39. Kondziolka, D.; Lacomis, D.; Niranjan, A.; Mori, Y.; Maesawa, S.; Fellows, W.; Lunsford, L.D. Histological effects of trigeminal nerve radiosurgery in a primate model: Implications for trigeminal neuralgia radiosurgery. Neurosurgery 2000, 46, 971-976.

40. Zhao, Z.F.; Yang, L.Z.; Jiang, C.L.; Zheng, Y.R.; Zhang, J.W. Gamma Knife irradiation-induced histopathological changes in the trigeminal nerves of rhesus monkeys. J. Neurosurg. 2010, 113, 39-44. [CrossRef]

(C) 2019 by the authors. Licensee MDPI, Basel, Switzerland. This article is an open access article distributed under the terms and conditions of the Creative Commons Attribution (CC BY) license (http://creativecommons.org/licenses/by/4.0/). 